This item was submitted to Loughborough's Research Repository by the author.

Items in Figshare are protected by copyright, with all rights reserved, unless otherwise indicated.

\title{
On understanding the nature of interpersonal conflict between coaches and athletes
}

\section{PLEASE CITE THE PUBLISHED VERSION}

https://doi.org/10.1080/02640414.2018.1428882

\section{PUBLISHER}

(c) Taylor \& Francis

\section{VERSION}

AM (Accepted Manuscript)

\section{PUBLISHER STATEMENT}

This work is made available according to the conditions of the Creative Commons Attribution-NonCommercialNoDerivatives 4.0 International (CC BY-NC-ND 4.0) licence. Full details of this licence are available at: https://creativecommons.org/licenses/by-nc-nd/4.0/

\section{LICENCE}

CC BY-NC-ND 4.0

\section{REPOSITORY RECORD}

Wachsmuth, Svenja, Sophia Jowett, and Chris Harwood. 2019. "On Understanding the Nature of Interpersonal Conflict Between Coaches and Athletes”. figshare. https://hdl.handle.net/2134/21913. 


\title{
On Understanding the Nature of Interpersonal Conflict between Coaches and Athletes
}

\author{
Svenja Wachsmuth $^{\mathrm{a} *}$, Sophia Jowett ${ }^{\mathrm{a}}$ and Chris G. Harwood ${ }^{\mathrm{a}}$ \\ ${ }^{a}$ School of Sport, Exercise and Health Sciences, Loughborough University, \\ Loughborough, UK
}

Paper submitted for publication in the Journal of Sport Science

Key words: coach-athlete relationship, disagreement, communication

Svenja Wachsmuth, School of Sport, Exercise and Health Science, Ashby Road, Loughborough University, Loughborough, Leicestershire LE11 3TU; Sophia Jowett, S.Jowett@1boro.ac.uk, School of Sport, Exercise and Health Science, Ashby Road, Loughborough University, Loughborough, Leicestershire LE11 3TU; Chris G.

Harwood, C.G.Harwood@1boro,ac.uk, School of Sport, Exercise and Health Science, Ashby Road, Loughborough Uniyersity, Loughborough, Leicestershire LE11 3TU

* Correspondence concerning this article should be addressed to Svenja Wachsmuth, School of Sport, Exercise and Health Science, Ashby Road, Loughborough University, Loughborough, Leicestershire LE11 3TU, United Kingdom. Email.:

$\underline{\text { S.Wachsmuth@1boro.ac.uk }}$ 
1 On Understanding the Nature of Interpersonal Conflict between

\section{Coaches and Athletes}

Conflict is a part of coach-athlete relationships and should be carefully considered as it can have effects on the quality of coaching and the level of performance. Despite its practical relevance, there is a dearth of research around coach-athlete conflict. Therefore, the current study aimed to explore the characteristics and topics of conflict, as well as coaches and athletes' emotional, cognitive and behavioural experiences during conflict. A total of 22 independent coaches and athletes participated in semistructured interviews evolving around the nature of interpersonal conflict. After all interviews were transcribed, a deductive-inductive content analysis was conducted. This was guided by the interview schedule as well as the by the conceptual framework of conflict in sport relationships (Wachsmuth, Jowett, \& Harwood, 2017). Data were divided into five main categories: Conflict characteristics and conflict topics, as well as conflict cognitions, emotions, and behaviours. Findings highlighted the variety of ways in which participants understood and interpreted interpersonal conflict and how their impressions of conflict influenced its evolving process. Considering the participants' cognitive, emotional and behavioural expressions of conflict, it became apparent that conflict can be described through uncertain, escalating and problem-orientated responses. Practical applications concerning (mal-) adaptive responses to conflict are discussed. (199/200)

Keywords: coach-athlete relationship, disagreement, communication

\section{Introduction}

The coach-athlete relationship is thought to be at the "heart of coaching" (Jowett

\& Shanmugam, 2016). Previous research has mainly addressed the benefits of positive, harmonious and stable coach-athlete partnerships that promote performances in training and competition (Antonini Philippe \& Seiler, 2006; Poczwardowski, Barott, \& Henschen, 2002), and enhance athletes' confidence, 
31 motivation, and well-being (e.g., Adie \& Jowett, 2010; Davis \& Jowett, 2014;

32 Jowett, 2008). While this research collectively suggests that high quality

33 relationships are associated with positive outcomes, limited research has explored

34 the consequences of less functional coach-athlete relationships marked with

35 conflict and dispute (e.g., Jowett, 2003).

36 While there is evidence to suggest that negative coaching, including

37 controlling, intimidating, and degrading behaviours, leads to low athlete

38 satisfaction, sport commitment, performance and mental health (e.g.,

39 Bartholomew, Ntoumanis, \& Thorgerson-Ntoumani, 2009; Gearity \& Murray,

40 2011; Hodge, Lonsdale, \& Ng, 2008; Shanmugam, Jowett, \& Meyer, 2014), there

41 is also evidence to suggest that conflict increases within coach-athlete

42 relationships that lack respect, trust, commitment and co-operation (Jowett, 2003,

43 2009). Previous findings suggest that conflict within coach-athlete dyads may be

44 promoted by relationship factors, such as insufficient communication, poor

45 leadership or unequal power distributions (e.g., Greenleaf, Gould, \& Diefenbach,

46 2001; Jowett, 2003; Purdy, Potrac, \& Jones, 2008). Conflict experienced in coach-

47 athlete dyads often seems to reflect divergent expectations and a general

48 breakdown of exchanges, leading to negative responses such as decreased

49 satisfaction, motivation and relationship effectiveness (e.g., Jowett, 2003; Jowett

$50 \&$ Carpenter, 2015). Such findings are consistent with Mellalieu, Shearer, and

51 Shearer's (2013) research which assessed determinants, nature and outcomes of

52 interpersonal conflict during major sport competitions. Results indicated that

53 conflict occurred due to communication breakdowns or power struggles and led to

54 positive, neutral and negative consequences in terms of emotions, cognition, and

55 performance. 
Although only few studies touch upon the construct of interpersonal

57 conflict in sport, a handful of studies have been carried out focusing on intra-

58 group conflict (e.g., Leo, Gonzalez-Ponce, Sanchez-Miguel, Ivarsson, \& Garcia-

59 Calvo, 2015; Paradis, Carron, \& Martin, 2014; Partridge \& Knapp, 2016). In line

60 with Mellalieu et al. (2013) and the general conflict literature (e.g., Barki \&

61 Hartwick, 2004), these studies describe intra-team conflict by negative emotions

62 (e.g., frustration, anger), thoughts (e.g., blame, disagreement) and behaviours

63 (e.g., screaming, ignoring). Intra-team conflict has, moreover, been divided into

64 task and social conflict (e.g., Holt, Knight, \& Zukiwski, 2012; Paradis et al.,

65 2014a). While task conflict usually concerns aspects of the sport including

66 performance, social conflict refers to relational issues, such as mutual dislike or

67 clashing personalities, and was found to be particularly dysfunctional for

68 relationships (Jehn, 1997).

69 Following a review of the literature, Wachsmuth, Jowett, and Harwood

70 (2017) define interpersonal conflict in sport as "a situation in which relationship

71 partners perceive a disagreement about, for example, values, needs, opinions or

72 objectives that is manifested through negative cognitive, affective and behavioural

73 reactions" (p. 88). This definition is accompanied by a conceptual framework of

74 interpersonal conflict in sport (see Figure 1). The framework displays conflict as a

75 dynamic process, whereby external, intra- and interpersonal determinants, as well

76 as conflict prevention strategies determine the onset and define the nature of

77 conflict. The nature of conflict, specifically, is described in terms of its content

78 (e.g., sport performance) and characteristics (e.g., intensity, duration), as well as

79 conflict parties' (e.g., coaches and athletes) emotional, cognitive and behavioural

80 experiences during conflict episodes. According to the framework, it is also 
81 proposed that the nature of conflict and conflict management attempts directly

82 predict the conflict outcomes (e.g., performance, relationship, wellbeing). This

83 theoretically driven conceptualization of interpersonal conflict in sports was put

84 forward with the intent to provide the impetus necessary to stimulate research into

85 this unexplored area within sport (Wachsmuth et al., 2017). While there is limited

86 evidence on the determinants and outcomes of conflict (e.g., Mellalieu et al.,

87 2013), empirical information about the nature of interpersonal conflict in sport

88 barely exists. The current study aims to fill this gap by investigating the nature of

89 coach-athlete conflict by exploring the following research questions: 1) What are

90 the characteristics and topics of coach-athlete conflict?, and 2) What are the

91 cognitive, emotional and behavioural processes experienced during conflict?

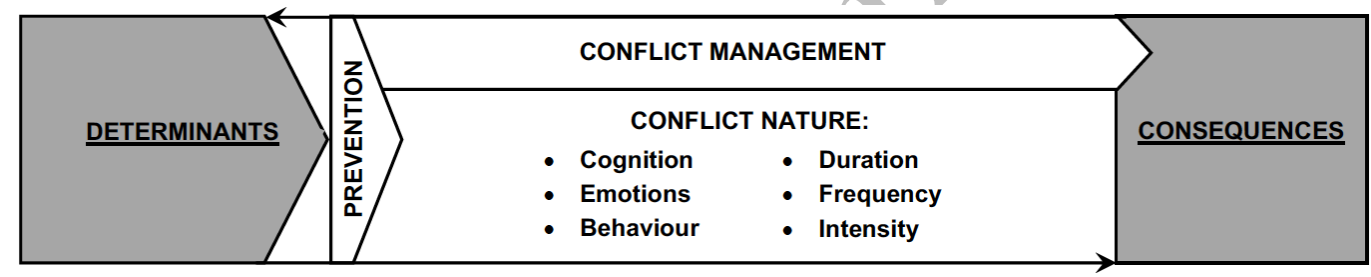

93 Figure 1. Conceptual framework of interpersonal conflict in sport relationships,

94 adapted from Wachsmuth et al., 2017

\section{Method}

\section{Participants}

97 A total of 22 coaches and athletes participated in the study based on the following

98 criteria: a) participants had to be at least 18 years of age, b) they previously

99 experienced conflict in coach-athlete relationships, and c) they participated at a

100 national performance level or higher. Data saturation was reached after eleven

101 coaches (9 male, 2 female) and eleven athletes ( 4 male, 7 female) were

102 interviewed (see Table 1). All individuals lived in the UK and were fluent English

103 speakers; three participants originated from Canada, Romania, and Slovenia. 
104 Table 1. Participants demographics

\begin{tabular}{|c|c|c|c|c|}
\hline & \multicolumn{2}{|c|}{ Coaches } & \multicolumn{2}{|c|}{ Athletes } \\
\hline & National & Internat. $* * *$ & National & Internat. $* * * *$ \\
\hline Individual* & 0 & 3 & 4 & 4 \\
\hline Team** & 3 & 5 & 1 & 2 \\
\hline$M_{\text {age }}$ & \multicolumn{2}{|c|}{45.80 years $( \pm 10.81)$} & \multicolumn{2}{|c|}{24.45 years $( \pm 3.31)$} \\
\hline$M_{\text {experience }}$ & \multicolumn{2}{|c|}{22.91 years $( \pm 12.95)$} & \multicolumn{2}{|c|}{13.09 years $( \pm 6.19)$} \\
\hline \multicolumn{5}{|c|}{$\begin{array}{l}\text { Notes: } \\
\text { * Individual sports: gymnastics, swimming, athletics, trampoline, canoeing; } \\
\text { ** Team sports: rugby, cricket, volleyball, curling, netball \& field hockey; } \\
\text { ***Breakdown coaches: } 8 \text { at World Cup level of which } 5 \text { coached Pard-/Olympic level athletes } \\
\text { **** Breakdown athletes: } 6 \text { competed in international competitions (e.g., Nation Cups and } \\
\text { Commonwealth Games) of which } 3 \text { participated also at World Cup level }\end{array}$} \\
\hline
\end{tabular}

\section{Data collection procedure}

112 Ethical approval was obtained from the ethics committee of the researchers'

113 institution. Potential interviewees were then approached via a standardized email

114 informing them about the purpose of the study, requirements of participation and

115 ethical considerations. Meetings took place at a mutually convenient time and

116 location; participants were asked to give informed consent and made aware that

117 the interview was audio-recorded. Demographic data (e.g., age, gender, sport) was

118 accessed with a brief questionnaire. As this research forms part of a larger project,

119 in this manuscript only data focused on the characteristics, nature and content of

120 conflict are presented. Overall, the semi-structured interview contained 26

121 questions covering five areas: sport experience, the personal meaning of conflict,

122 specific experiences of conflict, determining factors, and consequences; eight of

123 the 26 questions were relevant for this manuscript.

124 At the start of the interview, coaches and athletes were encouraged to 
125 share insights about their personal development within sports and experiences in

126 different coach-athlete relationships in order to build rapport with the interviewee.

127 They were further asked what conflict meant for them personally to establish a

128 shared understanding about the concept between researchers and participant (e.g.,

129 "What does coach-athlete conflict mean to you?"). Next, various topics of conflict

130 were explored, thus, stimulating participants' recall of multiple situations in which

131 they experienced conflict (e.g., "What is conflict with your coach/athlete

132 generally about?"). This was important as the following section focused on a

133 specific conflict event which the interviewee identified as significant and

134 described in rich detail (e.g., "Please think back to a situation in which you

135 experienced conflict with your coach/athlete, can you find a specific event that

136 you recall vividly? Tell me about it."; "What was the topic?”; "How did you

137 experience the conflict?"). Afterwards, participants were asked more specific

138 questions, for example, about the nature of conflict (e.g., "What are typical

139 behaviours you show during conflict?", "In your experience, what types of

140 conflict are more/less severe?’) in which they could draw on various conflict

141 experiences. Finally, coaches and athletes were invited to share any other thoughts

142 on the topic. Overall, the semi-structured nature of the interviews allowed for a

143 degree of flexibility (e.g., Sparkes \& Smith, 2014) enabling the researcher to

144 prompt the given information appropriately without interrupting the flow of the

145 conversation. When it became evident that data saturation was reached and no

146 new information emerged from the interviews, data collection was terminated

147 (Guest, Bunce, \& Johnson, 2006). Interviews lasted from 45 minutes to 2 hours 15

148 minutes $\left(M_{\text {coaches }}=80.0 \mathrm{~min} ; M_{\text {athletes }}=73.00 \mathrm{~min}\right)$ and added up to 888 pages of

149 double-spaced transcript, approximately $25 \%$ of the data was relevant to the 
150 current study.

\section{$151 \quad$ Data analysis}

152 A "directed content analysis" approach (Hsieh \& Shannon, 2005) was utilized to

153 examine all interviews individually, followed by a cross-case analysis of all

154 participants. According to Hsieh and Shannon (2005) a directed approach to

155 content analyses aims to "extend conceptually a theoretical framework or theory"

156 (p. 1281). Such an approach aligns with the present study as it aimed to

157 corroborate and further extend the conceptual framework of conflict in sport

158 relationships (Wachsmuth et al., 2017). This framework provided a rudimentary

159 coding scheme for data analyses. Subsequently, the coding scheme included the

160 main categories: conflict characteristics and topics, as well as emotional, cognitive

161 and behavioural responses. Sub-categories were added inductively throughout the

162 analytical process (cf., Hsieh \& Shannon, 2005; Krane, Andersen, \& Strean,

163 1997). A combination of a deductive and inductive analyses allowed the authors

164 to make sense of the participants' accounts by drawing parallels to existing

165 findings (e.g., Mellalieu et al., 2013) as well as by adding further insights and

166 details around the phenomenon under study.

167 The data analyses followed guidelines established in research (e.g., Hsieh

$168 \&$ Shannon, 2005). First, the principal researcher listened to and read all

169 interviews carefully to become fully familiar with the data. Second, relevant

170 extracts were identified and grouped according to the categories of the coding

171 scheme; this process has been called "deductive category application" (Mayring,

172 2000, cited in Hsieh \& Shannon, 2005). Third, general categories were then

173 further divided into sub-categories to provide a more meaningful analysis of the

174 data (e.g., topics of conflict; valence of emotions; Hsieh \& Shannon, 2005). 
175 Fourth, the identified categories were mapped out to facilitate a deeper

176 understanding of the data, its meaning and interconnectedness (Coffey \&

177 Atkinson, 1996). This final stage of sense making allowed the authors to draw

178 conclusions upon the underlying processes of interpersonal conflict in coach-

179 athlete dyads.

180 Tracey's (2010) criteria for excellent qualitative research (e.g., worthy

181 topic, rigour, credibility, ethics) were followed to ensure high quality standards of

182 the current study. Though limited space prevents an in-depth discussion of all

183 criteria, essential points referring to rich rigour and credibility are addressed.

184 Accordingly, an established stream of research into a) coach-athlete relationships

185 (e.g., Jowett, 2003, 2008, 2009) as well as b) interpersonal conflict (e.g., Barki \&

186 Hartwick, 2004; Wachsmuth et al., 2017) provided the theoretical foundations for

187 the design of the current study. Additionally, data was collected from diverse

188 participants (e.g., coaches/athletes; team/individual sport) with experience in the

189 area of inquiry (i.e., conflict). Thus, the gathered data offered rich accounts on the

190 phenomenon under study which is reflected within the quotes provided in this

191 manuscript. Credibility of the data analysis was further facilitated by the

192 involvement of the co-authors who acted as critical peers by offering different

193 perspectives and challenging the explanations and perceptions of the first author.

194 Dissensions resulting from this process were resolved by critical discussion as

195 well as by consulting conflict literature outside of sport (e.g., Fincham, Bradbury,

196 \& Grych, 1990; Sanford, 2012). Overall, the current research provides a

197 meaningful contribution to the literature by forwarding a detailed understanding

198 of coach-athlete conflict with significant practical implications. 


\section{Results}

200 Data were divided into the five main categories (Figure 2) describing the nature of

201 conflict by its characteristics and content (topics), as well as by cognitive,

202 emotional and behavioural aspects that were linked to the process of conflict.

203 Findings are illustrated using codes with examples as well as descriptive evidence

204 as it has been recommended by Hsieh and Shannon (2005).

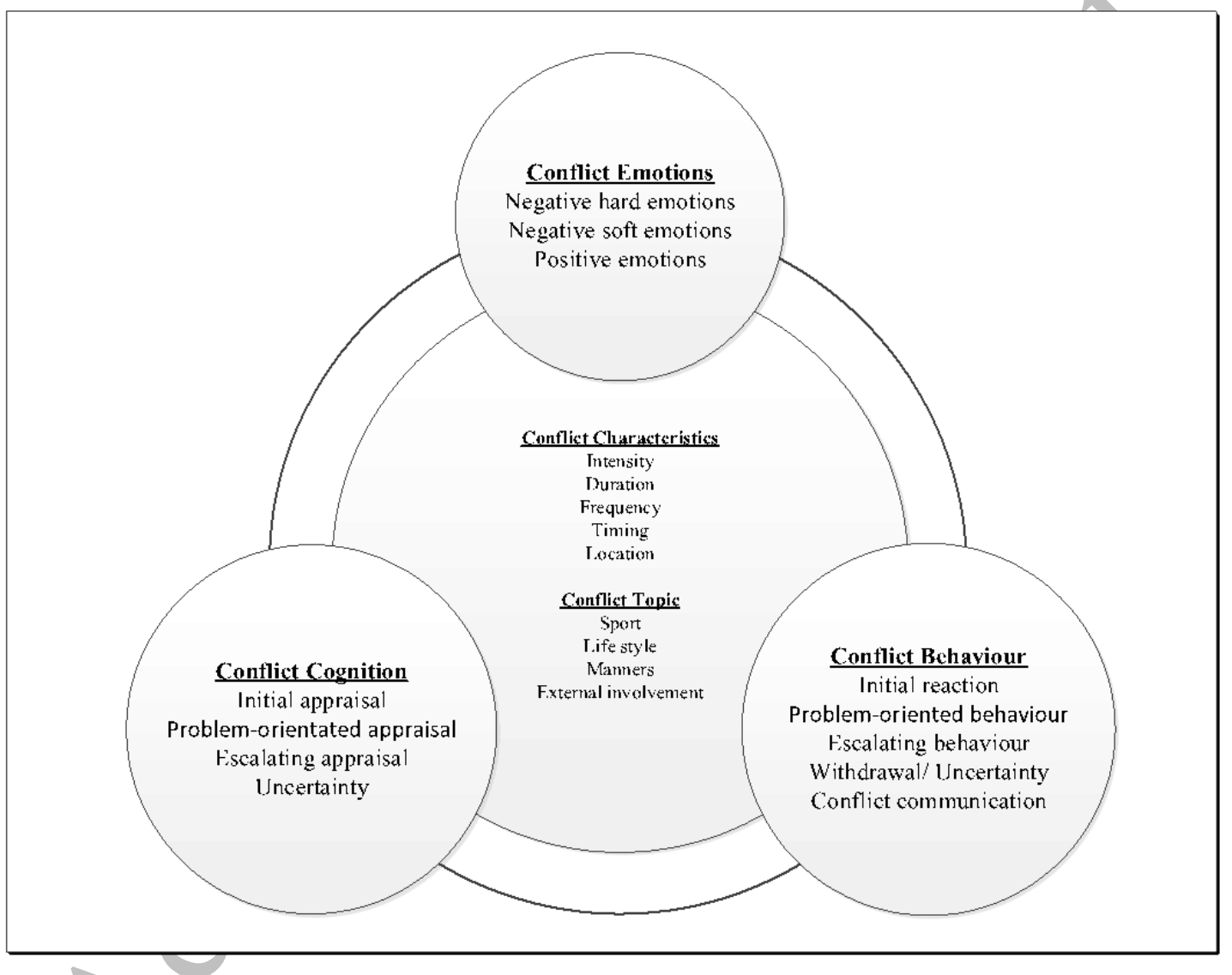

207 Figure 2: The categories and sub-categories describing the nature of conflict in 208 coach-athlete relationships.

\section{Conflict characteristics}

210 Participants described that interpersonal conflict ranged from mild to severe

211 (intensity), from lasting a short while (minutes) to long-term and ongoing

212 (months, years; duration), and from occurring barely ever to nearly every day 
213 (frequency; all deductive). Athlete 1 noticed that "most of [conflict] comes in the

214 build-up, in practice, cause you spend $95 \%$ of your time training with your coach

215 and there is just that 5\% in the competition." However, both coaches and athletes,

216 felt that conflict was likely to occur after competitions, especially when

217 expectations were not met. Further, conflicts occurred at all times of the season

218 (timing) and seemed to take place in various locations (both inductive), for

219 example, training grounds, the competition venue, in meetings, equipment rooms

220 and even in public (e.g., car park). Athlete 8 reported that conflict took place via

221 phone and email. Lastly, participants described the succession of events over time

222 leading to conflict onset, escalation and/or management: talked. I just decided to not work with that coach anymore, and we didn't really formally say anything, I just started working on my own. (A9)

\section{Conflict topics}

227 Participants perceived some conflicts as trivial (e.g., time management) and others

228 as crucial (e.g., injury) for the coach-athlete relationship, and as such directly

229 linked the conflict topic to its severity and process. Four different sub-categories

230 of conflict topics emerged inductively from the participants' reports: the majority

231 of conflicts concerned sport- and lifestyle-related topics, whereas some conflicts

232 related to individuals' misconduct and the involvement of external parties.

233 Sport-related conflict topics were perceived to be directly linked to either,

234 performance in practice or competition and included feedback, training schedules/

235 goals and load, injuries, individual ambitions, team selection and performance.

236 Also, role expectations and their fulfilment were a topic of concern: 

I don't get a reply, that's a massive problem. [...] if people were dropped from a game if that's not communicated [...] if people are not working hard in training or in matches and it's not picked up on, there's no point. (A4)

241 Further, lifestyle-related topics were recognized as a significant area of conflict

242 between coaches and athletes. They concerned behaviours manifested outside the

243 sport environment, however, they were thought to impact performance. On one

244 hand, athlete behaviours included poor nutrition, alcohol consumption or public

245 misbehaviour, and on the other hand coach behaviours included over-involvement

246 with private decisions (e.g., university, work). For example. Athlete 2 reported:

[Coach] tries to take [private life] away from me, makes it part of our relationship when it should be outside, work is something different to [sport], family, friends, but then [coach] almost tries to incooperate it.

250 Additionally, conflict arose as a result of misconduct; behaviours that were

251 perceived as disrespectful or inappropriate included, for example, being late,

252 physical aggression and "if people were lying" (C2), or "clashed with [each

253 other's] core values" (C6), as well as behaviours that targeted the other conflict

254 party on a personal level. Sometimes these conflicts arose out of unresolved sport-

255 related disagreements, thus, Coach 7 explained a sport- and lifestyle-related

256 conflict which escalated over time due to an athlete's misconduct: it running and you haven't done it running" you know, "We talked about your behaviours and your conduct and whether they were appropriate for what you are trying to achieve and you then were still going out and getting drunk and this resulted in you doing this [injury]. I gonna make a recommendation that you are taken off the programme." 
264 Lastly, some participants mentioned conflict could occur due to the involvement

265 of third parties, such as NGBs, other coaches or life partners as reported by Coach

26610 who described a dispute being "about potential external influences from a life

267 partner." Additionally, coach 5 pointed towards conflicts arising due to other

268 clubs trying to poach players stating that:

The guys are aspiring to play premiership rugby, so they get like drawn on by these clubs, and sudden like a drop form the heart, they are like "I can't, make training tonight, I'm training with [club]" and "How long have you known? We wanna help you with this, but you just ditched us within a drop of the heart" [...] external factors like that - it's like anything in the world, the packing order, the above us they click their fingers and these guys go ...

\section{Conflict cognition}

276 Conflict cognition represents thought processes that occur during conflict and are

277 linked to evaluations of the conflict situations. They may lead to conflict

278 escalation or facilitate an initiation of conflict management. It is conflict cognition

279 that captures thoughts that promote and hinder conflict management; all sub-

280 categories are a result of inductive data analyses.

281 Participants described how initial appraisal of the situation left them often 282 uncertain about the implications of a conflict event, doubting "What can I do?"

283 (A10), thinking negatively of the other, helpless, insecure or worried. For

284 instance, Coach 6 wondered "Did she use me to get here?"

285 During this evaluation process individuals ascribed the conflict experience

286 to a specific source (attribution). Thus, conflict was either attributed internally to 287 oneself (e.g., admitting a mistake), to the conflict partner (e.g., blaming) or both, 288 as well as to external circumstances (e.g., stress due to an upcoming competition 289 or travelling). The initial attribution often differed from an attribution made at a 
290 later point of time during conflict. For example, Coach 6 described a specific

291 conflict with an athlete, she initially reasoned that the difficulties they had were

292 due to mental health issues, though subsequently she reasoned the lack of effort

293 was at the heart of the problems they had. The coach said "I thought it's because

294 of [athlete] learning behaviours and learning difficulties, and you really got to

295 help the best in that, but actually they're [expected characteristics] not there."

296 Following this first appraisal of the conflict, participants explained on how

297 this preliminary reflection influenced their behaviour. For example, a negative

298 evaluation of the situation often seemed to lead to further conflict escalating

299 behaviours and ineffective communication strategies. In turn, a conflict escalating

300 appraisal was linked to disbelief, a perception of unfair treatment, "personal

301 attack" (C6), or blaming the other conflict party for the conflict:

I felt like he'd been unfair cause we had no idea what was going on, but he obviously, he did feel, like I can understand why he'd be annoyed if he thought that other people had heard because he'd see that as undermining him which is fair enough. (A6)

306 Uncertainty, on the other hand, was linked to withdrawal behaviours and was

307 experienced by most athletes as worry and doubt about oneself, the other and/or

308 the relationship; Athlete 5 described "I always felt not important enough, like

309 'you are not good enough for me to be seen with you." Similarly, few coaches

310 contemplated their influence upon the individual or even team, like Coach 4 who

311 said "I thought a few weeks ago that potentially I had lost the changing room and

312 when you lose the changing room it's not a pleasant environment." Lastly, a

313 constructive problem-orientated appraisal, emphasized especially by coaches,

314 was associated with an attempt to minimize conflict, and included thought

315 processes such as considering the importance of the topic, prioritizing goals as 
316 well as taking the conflict partners' perspective or being concerned about the

317 other's feelings. For example, coach 5 expressed empathy for an athlete thinking

318 that "he is just angry and quite upset [...] because it's a big deal for this guy, he's

319 missing out and lashing out, it's the final."

\section{Conflict emotion}

321 Conflict emotion describes affective responses that individuals experience during

322 interpersonal conflict. Emotions were linked to conscious and subconscious

323 cognitive processes and served as a barometer to conflict escalation. Guided by

324 the data it was noticeable that these conflict-related emotions were distinguished

325 in three categories: negative hard emotions, negative soft emotions and positive

326 emotions (inductive; see Sanford, 2012). Participants referred to different

327 emotional experiences during conflict. Negative emotions seemed to range from

328 hard, associated with power and selfishness (e.g., "I was quite annoyed, I was a

329 bit boiling" - C2), to soft emotions, associated with pro-social orientations and

330 vulnerability (e.g., "I was just more gutted for him" - C4). Overall, the negative

331 emotions experienced during conflict varied from strong, acute feelings (e.g.,

332 anger, panic) to ongoing frustration, resentment and worry. Especially, athletes

333 mentioned how they became nervous or anxious in interpersonal exchanges with

334 the coach in practice session and/or in meetings. Moreover, participants frequently

335 reported feelings of regret as a consequence of conflict. Coach 7, for example,

336 described that the athlete "was very remorseful and recognized that [he] failed me

337 as well as failing themselves."

338 Some positive emotions were also experienced with conflict situations.

339 While some coaches felt calm and collected, like Coach 9 who stated "I was quiet,

340 I was in control, quite calm, quite okay.”, athletes reported feeling relieved and 
341 reassured. Athlete 3 said "I saw it coming for quite a while, so it was quite a

342 release for me.”, and Athlete 6 perceived conflict as a chance to overcome

343 communication barriers stating that "it was kinda relief in a way that there is some

344 form of ice broken and we could then just discuss it."

\section{Conflict behaviour}

346 The experienced emotions and cognitions were often accompanied by conflict

347 behaviours displaying either uncertainty, escalation, or problem-orientation.

348 These were mainly expressed through active communication processes between

349 coaches and athletes during the time of conflict (all inductive). What seemed to

350 make a difference in the development of conflict was not the one person who

351 initiated it, but how the other person responded.

352 Thus, participants reported behaviours that prevented conflict from

353 escalating by actively approaching the problem (problem-orientation). For

354 example, Coach 1 reported "I asked her to explain what she meant with

355 inconsistencies, and I tried to explain to her that this was my thought process and

356 she was absolutely entitled to disagree." It was evident from the interviews that

357 coaches tended to react in a more controlled manner and either stepped away from

358 the problem or facilitated rational thinking in the early stages.

359 In contrast, athletes' reactions could be described as more negative and

360 less adaptive or skilful; behaviours included crying, refusing to talk, making

361 irrational excuses, shouting, answering back or not adhering to instructions.

362 Athlete 9 said 'I would just say 'Okay' and do my own thing, avoid doing that

363 thing [...] or I wouldn't do it to my full ability." However, there were also times in

364 which coaches employed less then desirable behaviours by shouting at their

365 athletes or using inappropriate language. Such escalating behaviours mentioned 
366 by participants also included swearing, ignoring the other, involving third parties,

367 not taking responsibility or being unwilling during conflict management. Other

368 escalating behaviours related to the communication style between coaches and

369 athletes during conflict: rhetorical questions, a harsh tone, loud voice, and giving

370 an opinion in a firm or confident manner and standing up for one's point of view: you are thinking rationally, you'd be like "Bit risky to say that", whereas when you're upset about something you'd say more because it's almost like "Oh they said it because they're upset", so it's easier. (A6)

375 Other examples of less than optimal behaviours related to one's experience of

376 uncertainty included athletes deciding to neither engage in nor trying to solve the

377 problem, but instead withdrawing from the situation. Thus, a common strategy

378 among them was to not address the problem, especially if they could not envisage

379 a solution. For instance, Athlete 2 explained that their coach "is a very intelligent

380 man and whatever you said [coach] would have a comeback for it, so it's just not

381 worth it." These behaviours of uncertainty that contained an element of

382 resignation, insecurity or vulnerability seemed to worsen conflict, especially

383 during a long-lasting conflict. Coach 4 reported "I didn't answer questions well, I

384 felt like I was on the back foot, really the baddest of feelings [...] I didn't have an

385 answer for him.”

\section{Discussion}

387 Guided by the framework of interpersonal conflict in sport relationships

388 (Wachsmuth et al., 2017) the current study aimed at understanding the nature of

389 coach-athlete conflict. In line with Wachsmuth et al. (2017), the qualitative data

390 revealed that when the topic of conflict was considered to be significant and the 
391 relationship partner was identified as the source of interference or disagreement,

392 coaches and athletes were likely to manifest cognitive (e.g., blame), emotional

393 (e.g., anger) and behavioural (e.g., shouting) conflict responses which influenced

394 the characteristics of conflict. These findings are consistent with the multi-

395 dimensional nature of conflict reported in the literature (Barki \& Hartwick, 2004;

396 Paradis et al., 2014a, 2014b; Wachsmuth et al., 2017).

397 Conflict topic and characteristics

398 Participants highlighted that the topic of conflict influenced the conflict processes

399 as reflected in the behavioural, emotional and cognitive responses which in turn

400 seemed to be linked to conflict characteristics such as intensity and/or duration. It

401 was reported that deeply rooted or external conflicts (e.g., influence of life

402 partner) intensified the situation and were harder to resolve than internal conflicts

403 (e.g., training load). Four main topics emerged from the participants' reports and

404 included sport- and lifestyle-related topics as well as one's misconduct or

405 manners, and involvement of third parties. Considering the dichotomy provided

406 by Barki and Hartwick (2004), sport- and lifestyle-related topics mainly reflected

407 task conflicts, whereas ones' misconduct and manners reflected social conflicts.

408 Consistent with research in both social and sport psychology (e.g., Amason, 1996;

409 de Wit, Greer, \& Jehn, 2012; Jowett, 2003), the current findings indicate that it

410 was common for task and social conflicts to co-occur and/or merge. Overall,

411 coaches and athletes referred more often to task conflicts than to social conflicts,

412 which contradicts with the findings of Holt and colleagues' who reported a higher

413 number of social conflicts within female sport teams (Holt et al., 2012).

414 Considering that coach-athlete relationships are task purposeful (Jowett \&

415 Shanmugam, 2016) and so coaches and athletes strive for performance 
416 achievements often agreed and understood by both, this finding is not too

417 surprising. Besides, females operating in team sports emphasize the importance of

418 strong personal relationships and thus may create an environment in which social

419 conflicts are likely to erupt (Eys et al., 2015). Our study, however, did not

420 specifically examine gender differences.

421 Lastly, the setting and time in which conflict arises should be taken into

422 account. In contrast to Mellalieu et al. (2013) the current findings indicate that the

423 majority of conflict took place within training or individual meetings rather than

424 during competition or within social settings. Additionally, it seemed that the time

425 of the season influenced the occurrence of conflict. However, more research is

426 needed which investigates the determinants and outcomes linked to particular

427 conflict characteristics.

\section{Coaches and athletes' responses to conflict}

429 The current study further extents the existing work on conflict within sport

430 relationships, which often presented a positive-negative dichotomy of conflict

431 responses (cf. Wachsmuth et al., 2017), by highlighting multiple levels in which

432 coaches and athletes processed conflict resulting in diverse behavioural options

433 during conflict episodes. An initial appraisal to the onset of conflict occurred

434 spontaneously and was based on identifying the event as significant (or not) to

435 themselves (cf. Fincham et al., 1990). Secondly, a more in-depth evaluation

436 followed leading either escalating, uncertain or problem-oriented conflict

437 responses. Accordingly, it emerged that attributions of accountability were linked

438 to behaviours and emotions experienced. For example, blaming the conflict

439 partner was part of an escalating response linked to negative hard emotions (e.g.,

440 feeling angry) and aggressive behaviours (e.g., yelling), which in turn intensified 
441 and prolonged conflict (Holt et al., 2012; Paradis et al., 2014a; Patridge \& Knapp,

442 2016). In addition, a perceived lack of control and influence (e.g., self-doubt) was

443 linked to withdrawal behaviours and negative soft emotions (e.g., disappointment,

444 worry), forming uncertain responses to conflict. In contrast to previous research

445 (cf. Wachsmuth et al., 2017), some participants also referred to the experience of

446 positive emotions (e.g., relief) and attempted to approach the problem at both a

447 cognitive and behavioural level. This set of experiences and others alike seem to

448 encompass problem-orientated responses to conflict.

449 Overall, the three identified response patterns are in contrast to what

450 Partridge and Knapp (2016) describes as the manifestation of conflict. In their

451 study on peer conflict in adolescent sport the authors approach conflict through a

452 behavioural perspective highlighting victimization at the centre of conflict, while

453 not considering related emotional and cognitive processes in either victim or

454 perpetrator. Moreover, the representation of conflict as victimization rather aligns

455 with bullying or emotional abuse, which indeed may cause or accompany conflict,

456 but embody distinct concepts (Stirling, 2009). The findings of the current study,

457 however, indicate that conflict responses of emotions, thoughts and behaviours

458 appeared to be inextricably interlinked and so one dyad member's responses

459 fuelled another member's responses, reflecting high interdependency of conflict

460 partners and as such support the self-reinforcing feedback loop described by

461 Roberts (2006). In contrast to Roberts, however, this reciprocity seemed to occur

462 for both, dysfunctional as well as functional responses to conflict. Considering

463 that problem-oriented responses were primarily shown by coaches; this difference

464 may be explained by the hierarchical relationship and role expectations (Potrac \&

465 Jones, 2009). However, there is more scope for research in this area. 
467 This study represents the first systematic approach to examining interpersonal 468 conflict in the context of coach-athlete relationships. Even though initial results

469 shed light on the complexity of this line of inquiry, there is substantial need for

470 further investigations. Future research should, for example, advance conflict

471 knowledge by collecting data from entire coach-athlete dyads as there is initial

472 evidence within the current data suggesting that perceptions of specific conflict

473 events differ between them. Additionally, the gender composition, culture and

474 type of relationship (e.g., typical vs atypical; see Jowett \& Meek, 2000) requires

475 further investigation. In future, different sample characteristics, such as length of

476 relationship, performance level, sport type or training set-ups (e.g., training

477 camps, training group) may also be worth investigating. The development of a

478 psychometric tool to measure the nature of conflict in coach-athlete relationship

479 may help generate knowledge about its antecedents and consequences employing

480 cross-sectional, longitudinal and experimental research. Further work that

481 warrants attention may also target specific questions such as: Are frequent

482 conflicts detrimental to the partnership between coaches and athletes even if

483 resolved? How does conflict influence athletes and coaches' wellbeing?

484 In summary, interpersonal conflict presents researchers in sport with a

485 relatively new theoretical and empirical as well as measurement challenge.

486 Clearly there is ample scope to explore and thus discover. The present study

487 contributes to this new field of investigation by exploring nature and topics of

488 conflict. Several recommendations can be concluded that enable practitioners to 489 approach conflict constructively and as such enhance the effectiveness of coach490 athlete dyads. Conflict is inevitable in any kind of relationships, and thus it is 
491 important to increase coaches and athletes' awareness and highlight that while

492 conflict can be detrimental, it may also be beneficial if it is approached in a

493 manner that is functional. It has been highlighted how conflict-related cognitions,

494 emotions, and behaviours manifest both separately and together over time and as

495 such influence the course of conflict. Thus, responding to conflicts with self-

496 doubt, insecurity and withdrawal (uncertain response), or even angry,

497 aggressively and self-centred (escalating response) may lead to an escalation of

498 conflict, whereas a more problem-oriented, caring approach connected with a

499 sense of calmness and relief potentially facilitates coping and conflict

500 management. Overall, the current study provides a first attempt to closely

501 investigate conflict between coaches and athletes within the context of their

502 dyadic relationships and paves the way for enhancing the body of research within 503 this field. 


\section{References}

Adie, J., \& Jowett, S. (2010). Meta-perceptions of the coach-athlete relationship, achievement goals, and intrinsic motivation among sport participants. Journal of Applied Social Psychology, 40(11), 2750-2773. doi:10.1111/j.1559-1816.2010.00679.x/full

Amason, A. C. (1996). Distinguishing the effects of functional and dysfunctional conflict on strategic decision making: Resolving a paradox for top management teams. Academy of Management Journal, 39(1), 123-148. doi: $10.2307 / 256633$

Antonini Philippe, R., \& Seiler, R. (2006). Closeness, co-orientation and complementarity in coach-athlete relationships: What male swimmers say about their male coaches. Psychology of Sport and Exercise, 7(2), 159171. doi: 10.1016/j.psychsport.2005.08.004

Barki, H., \& Hartwick, J. (2004)/Conceptualizing the construct of interpersonal conflict. The International Journal of Conflict Management, 15(3), 216244. doi:10.1108/eb022913

Bartholomew, K. J., Ntoumanis, N., \& Thøgersen-Ntoumani, C. (2009). A review of controlling motivational strategies from a self-determination theory perspective: Implications for sports coaches. International Review of Sport and Exercise Psychology, 2(2), 215-233. doi:10.1080/17509840903235330

Coffey, A., \& Atkinson, P. (1996). Making sense of qualitative data. Thousand Oaks: Sage Publications, Inc. 
527 Davis, L., \& Jowett, S. (2014). Coach-athlete attachment and the quality of the coach-athlete relationship: Implications for athlete's well-being. Journal of Sports Sciences, 32(15), 1454-1464. doi:10.1080/02640414.2014.898183

De Wit, F. R., Greer, L. L., \& Jehn, K. A. (2012). The paradox of intragroup

Eyes, M., Evans, B. M., Martin, L. J., Ohlert, J., Wolf, S. A., van Bussel, M., \& Steins, C. (2015). Cohesion and performance for female and male sport teams. The Sport Psychologist, 29(2), 97-109. doi: 10.1123/tsp.2014-0027 conflict: A meta-analysis. Journal of Applied Psychology, 97(2), 360. doi: $10.1037 / \mathrm{a} 0024844$

Gearity, B. T., \& Murray, M. A. (2011). Athletes' experiences of the psychological effects of poor coaching. Psychology of Sport \& Exercise,

Greenleaf, C., Gould, D., \& Dieffenbach, K. (2001). Factors influencing Olympic performance: Interviews with Atlanta and Nagano US Olympians. Journal

548 Guest, G., Bunce, A., \& Johnson, L. (2006). How many interviews are enough? of Applied Sport Psychology, 13(2), 154-184. An experiment with data saturation and variability. Field Methods, 18(1), 59-82. Doi: 10.1177/1525822X05279903 
551 Hsieh, H. F., \& Shannon, S. E. (2005). Three approaches to qualitative content analysis. Qualitative Health Research, 15(9), 1277-1288.

553 Hodge, K., Lonsdale, C., \& Ng, J. Y. (2008). Burnout in elite rugby:

554 Relationships with basic psychological needs fulfilment. Journal of Sports

$555 \quad$ Sciences, 26(8), 835-844. doi:10.1080/02640410701784525

556 Holt, N., Knight, C., \& Zukiwski, P. (2012). Female athletes' perceptions of teammate conflict in sport: Implications for sport psychology consultants. The Sport Psychologist, 26, 135-154.

559 Jehn, K. A. (1997). A qualitative analysis of conflict types and dimensions in $560 \quad$ organizational groups. Administrative Science Quarterly, 42(3), 530-557.

561 Jowett, S. (2003). When the "honeymoon" is over: A case study of a coach-athlete dyad in crisis. The Sports Psychologist, 17, 444-460.

563 Jowett, S. (2008). Moderators and mediators of the association between the coachathlete relationship and physical self-concept. International Journal of Coaching Science, 2, 43-62.

Jowett, S. (2009). Validating coach-athlete relationship measures with the

572 Jowett, S., \& Shanmugam, V. (2016). Relational Coaching in Sport: Its psychological underpinnings and practical effectiveness. In R. Schinke, Psychology. Routledge. 
576 Krane, V., Andersen, M. B., \& Strean, W. B. (1997). Issues of qualitative research methods and presentation. Journal of Sport \& Exercise Psychology, 19, $213-218$.

Leo, F. M., González-Ponce, I., Sánchez-Miguel, P. A., Ivarsson, A., \& GarcíaCalvo, T. (2015). Role ambiguity, role conflict, team conflict, cohesion and collective efficacy in sport teams: A multilevel analysis. Psychology of Sport \& Exercise, 20, 60-66. doi: 10.1016/j.psychsport.2015.04.009 interpersonal conflict at major games and championships. The Sports Psychologist, 27, 120-129.

Paradis, K. F., Carron, A. V, \& Martin, L. J. (2014a). Athlete perceptions of intra-

Paradis, K., Carron, A., \& Martin, L. (2014b). Development and validation of an group conflict in sport teams. Sport \& Exercise Psychology Review, 10(3),

Partridge, J. A., \& Knapp, B. A. (2016). Mean Girls: Adolescent female athletes and peer conflict in sport. Journal of Applied Sport Psychology, 28(1),

596 Poczwardowski, A., Barott, J. E., \& Henschen, K. P. (2002). The athlete and coach: Their relationship and its meaning. Results of an interpretive study. International Journal of Sport Psychology, 33(1), 116-140. 
599 Potrac, P., \& Jones, R. (2009). Power, conflict, and cooperation: Toward a

600

601

602

603

604

605

606

607

608

609

610

611

612

613

614

615

616

617

618 Sparkes, A. C., \& Smith, B. (2014). Qualitative research methods in sport,

micropolitics of coaching. Quest, 61(2), 223-236.

$$
\text { doi:10.1080/00336297.2009.10483612 }
$$

Purdy, L., Potrac, P., \& Jones, R. (2008). Power, consent and resistance: An autoethnography of competitive rowing. Sport, Education and Society, 13(3), 319-336. doi:10.1080/13573320802200693

Roberts, L. J. (2006). From bickering to battering: Destructive conflict processes in intimate relationships. In P. Noller and J. A. Feeney (Eds.) Close Relationships: Functions, Forms and Processes. Psychology Press: New York.

Sanford, K. (2012). The communication of emotion during conflict in married couples. Journal of Family Psychology, 26(3), 297. doi:10.1037/a0028139

Shanmugam, V., Jowett, S., \& Meyer, C. (2014). Interpersonal difficulties as a risk factor for athletes' eating psychopathology. Scandinavian Journal of Medicine \& Science in Sports, 24(2), 469-76. doi:10.1111/sms.12109

Smith, B., \& Caddick, N. (2012). Qualitative methods in sport: A concise overview for guiding social scientific sport research. Asia Pacific Journal of Sport and Social Science, 1(1), 60-73. doi: $10.1080 / 21640599.2012 .701373$ exercise and health. London: Routledge.

Stirling, A. E. (2009). Definition and constituents of maltreatment in sport: Establishing a conceptual framework for research practitioners. British Journal of Sports Medicine, 43(14), 1091-1099. Doi:

10.1136/bjsm.2008.051433 
624 Tracy, S. J. (2010). Qualitative quality: Eight "big-tent" criteria for excellent

625 qualitative research. Qualitative Inquiry, 16(10), 837-851.

626 Wachsmuth, S., Jowett, S., \& Harwood, C. (2017). Conflict among athletes and

627 their coaches: What is the theory and research so far? International Review

628 of Sport and Exercise Psychology, 10(1), 84-107.

629 doi:10.1080/1750984X.2016.1184 


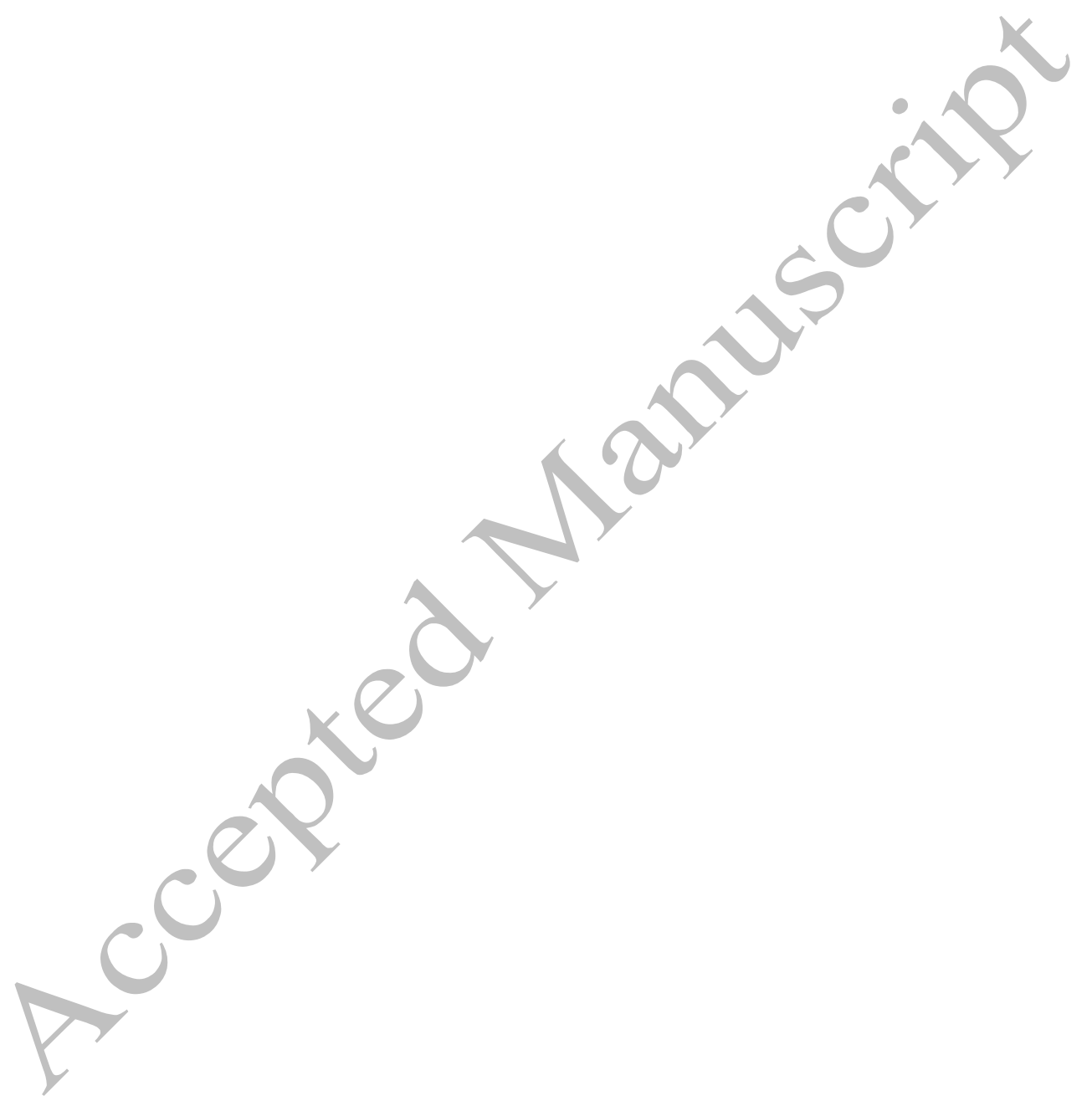




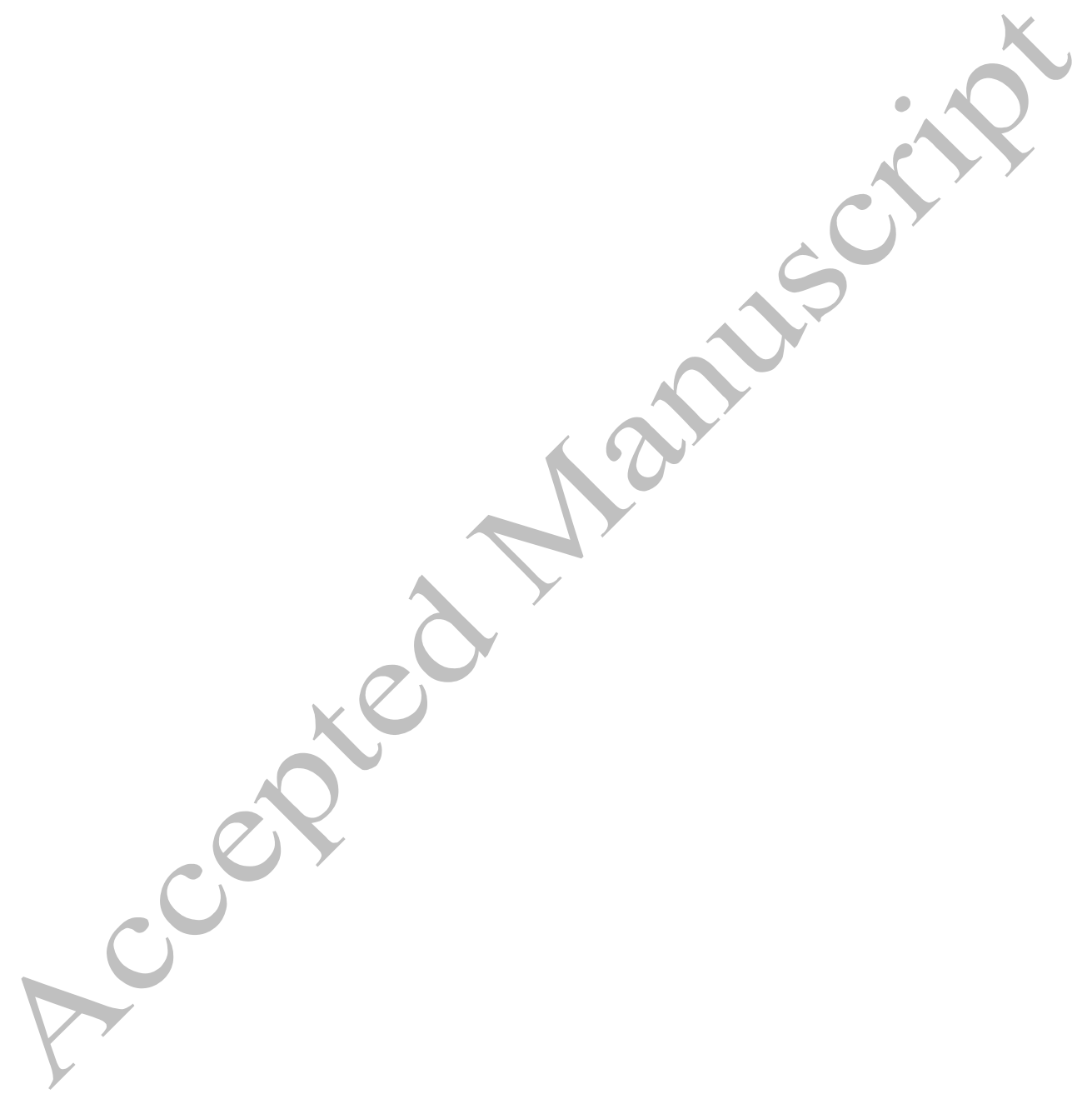

